\title{
A INTEGRAÇÃO DA AGRICULTURA FAMILIAR E ECONOMIA POPULAR E SOLIDÁRIA: UMA ANÁLISE DOS GRUPOS RURAIS POTENCIAIS FORNECEDORES DE ALIMENTOS ÀS CANTINAS SOLIDÁRIAS DA UEFS. Angélica Correia Lopes'; José Raimundo Oliveira Lima².
}

\author{
1. Bolsista PIBIC/CNPq, Graduanda em Agronomia, Universidade Estadual de Feira de Santana, e-mail: \\ angelica.correia13@hotmail.com \\ 2. Orientador, Departamento de Ciências Sociais Aplicadas, Universidade Estadual de Feira de Santana, e-mail: \\ zeraimundo@uefs.br
}

PALAVRA -CHAVE: Economia Popular e Solidária; Agricultura Familiar; Cantina Solidária

\section{INTRODUÇÃO}

A Incubadora de Iniciativas da Economia Popular e Solidária da Universidade Estadual de Feira de Santana (IEPS/UEFS) busca a interação e laços de solidariedade que se traduzem em benefícios sociais para o desenvolvimento da comunidade em ação, especialmente pelo envolvimento e valorização dos saberes locais, culturas locais e tecnologias que se reúnem em benefício de outra forma de desenvolvimento que não o modelo tradicional. (PITA, F.; LIMA, J. R. O.; LIMA, C. E. S., 2015). O Programa Incubadora de Iniciativas da Economia Popular e Solidária (PIEPS/UEFS) foi criado formalmente em 2008 numa proposta de interdisciplinaridade tornando-se um Programa de Extensão de caráter contínuo articulando com um Projeto de Pesquisa no mesmo espaço com os mesmos sujeitos. Essas atividades de pesquisa e extensão desenvolvem ações pautadas nas vertentes da economia popular e solidária.

Desta forma, a economia popular e solidária assume papel importante na transformação de sujeitos, que buscam nessa "outra economia", conforme discute Lima (2016), uma forma de geração de trabalho e renda, exercida de forma coletiva e que não visa apenas à lucratividade, mas um conjunto de aspectos que estabeleçam uma relação estreita entre trabalho e qualidade de vida, ambos como peças importantes neste processo viabilizando as relações entre o modo de consumir, pensar e agir do ser humano.

Atualmente a Incubadora acompanha quatro iniciativas que passam pelo processo de incubação, sendo que duas delas desenvolvem suas ações econômicas nos espaços das cantinas (módulo I e VII), cedidas pela universidade à incubadora como espaço pedagógico para realização do projeto Cantina Solidária, tendo como principal objetivo fornecer produtos alimentícios levando em consideração o contexto sociocultural no qual estão inseridos contribuindo com o desenvolvimento local do município de Feira de Santana.

A utilização de produtos de origem da agricultura familiar ou base agroecológica, possibilita uma forma de consumo sustentável, que garante a valorização da produção local, garantia de mercado e geração de renda interna, como forma de acondicionamento de recursos e poder no desenvolvimento de uma comunidade, conforme discute Lima (2012), especialmente, em relação à construção de um processo político educativo que leva á comunidade a defesa orgânica de uma forma de desenvolvimento endógena.

Para Motta (2007), a integração da agricultura familiar com a economia solidária, mais que resulta em soluções de pequena escala, pode ser uma alternativa de desenvolvimento mais saudável para o país, tanto em termos econômicos como sociais e culturais, entre campo e cidade.

O presente trabalho faz uma abordagem da execução do plano de pesquisa em iniciação científica durante o ano de 2016/2017 trazendo uma abordagem do período de agosto de 2016 até julho de 2017, organizado em: materiais e métodos pesquisa, buscando ampliar a integração entre pesquisa e extensão, visando à valorização dos produtos locais através do mapeamento de grupos rurais e o fortalecimento da relação agricultura familiar e economia popular e solidária 
no município de Feira de Santana cooperando com as atividades da IEPS para a estruturação e formação do banco de dados.

\section{METODOLOGIA}

Para a execução do plano de trabalho adotou-se a Metodologia da Pesquisa Participativa, que combina traços de pesquisa e extensão é a mesma que já vem sendo aplicada pelo Projeto de Incubadora de Iniciativas da Economia Popular e Solidária-IEPS /UEFS, em que de acordo com Brandão (1999), pesquisadores e pesquisados são sujeitos de um mesmo trabalho comum, ainda que com situações e tarefas diferentes.

A pesquisa utilizou-se de levantamento bibliográfico, que forneceu um suporte teórico; sobre a temática abordada, onde foram efetuadas leituras de autores como: Metodologia Participativa (Brandão 2007) e Pesquisa Participante (Thiolent 1998); Elaboração de Entrevista Semiestruturada (Souza 2009); Economia Popular e Solidária e Desenvolvimento Local ( Lima 2012 e Lima 2016); Economia Popular e Solidária ,Agricultura Familiar (Motta 2007), Desenvolvimento Rural ( Carmo 1998) e entre outros, além de uma complementação teórica fornecida através de discussões do Grupo de Estudos e Pesquisa em Economia Popular e Solidária e Desenvolvimento Local (Geposdel).

Inicialmente foi adotado o planejamento de atividades a serem executadas, onde foi elaborado os preparativos para a etapa posterior, como por exemplo: elaboração de entrevistadas semiestruturadas, escolha dos lugares a serem investigados/visitados. O desenvolvimento da pesquisa foi voltado principalmente para o Projeto Cantina Solidária III que teve o início de suas atividades em julho de 2016 formado pelo Grupo Sabores do Quilombo, em sua maioria mulheres, oriundas da zona rural de um distrito de Feira de Santana, remanescentes de uma comunidade quilombola, que além de priorizar elementos regionais e culturais na produção dos alimentos comercializados nos espaços da cantina tem como alguns de seus fornecedores de matéria prima, os próprios agricultores da comunidade fortalecendo a rede de produção e comercialização local. Sendo feito a escolha pelo fato de o grupo está iniciando suas atividades de incubação o que permitiria um melhor acompanhamento do grupo durante a execução da pesquisa.

O levantamento de dados e informações da pesquisa se constituiu em elementos de base para a análises de dados internos e externos. Em relação a obtenção de dados internos foram utilizados materiais das fichas de inscrição e ou entrevistas realizadas pela equipe IEPS durante a realização das feiras dos eventos que ocorreram dentro do espaço da Universidade Estadual de Feira de Santana (UEFS): Feira de Cultura e Produção Camponesa (setembro/2015); I Feira de Economia Popular e Solidária da UEFS (março /2016); e X Feira do Semiárido (outubro/2016) entre o período de 2015 e 2016 atendendo ao objetivo identificação de grupos rurais envolvidos com princípios da Economia Popular e Solidária que trabalhem com alimentação.

Os dados externos foram adquiridos através da entrevista semiestrutura elaborada para o mapeamento com os agricultores familiares da Comunidade Quilombola da Lagoa Grande (distante da sede do distrito em cerca de $1,5 \mathrm{~km}$ e do centro da sede municipal em $17 \mathrm{~km}$ ), apresentam cerca de 140 famílias, está localizada no Distrito de Maria Quitéria (São José),um dos oito distritos, além do distrito sede, que integram Feira de Santana .Hoje, a condição de Comunidade Quilombola, que após muita luta, já foi reconhecida como território quilombola pelo Município e pela fundação Palmares, em 2007, que agora está à espera da oficialização pelo INCRA para tornar a atual escola local uma escola quilombola. A escolha dessa comunidade se deu, pelo fato do grupo atuante no Projeto Cantina III, Sabores do Quilombo, ser originado desta comunidade, sendo esta uma possível potencial na produção agrícola. As entrevistas foram aplicadas entre o período de 07 de março de 2017 a 12 de junho de 2017. 
E por fim, realizou a conclusão de análise e interpretação de dados para a implantação do banco de dados.

\section{RESULTADOS E DISCUSSÕES}

Através dos dados obtidos foi realizado a construção do Banco de Dados da IEPS utilizando o programa Microsoft Access (Microsoft Office Access) também conhecido por MSAccess, que é um Sistema de gerenciamento de banco de dados da Microsoft, incluído no pacote da Microsoft. A escolha do programa baseou-se pela interface simples apresentada pelo o programa permitido aos usuários que não apresentam tanto domínio com programação. A construção do Banco de Dados da IEPS divide em duas etapas uma que atende ao princípio da organização de arquivos físicos no caso dos grupos, e a outra ao princípio de formação de rede de comercialização para os grupos em processo de incubação no espaço das Cantinas Solidárias.

A primeira etapa do banco de dados foi iniciada em janeiro de 2017 onde foi criado um banco de dados intitulado: "Grupos" onde foram inseridos os grupos que trabalham com alimentação dentro da cidade de Feira de Santana. As informações que construíram o banco foram: nome do grupo, endereço, contato, produtos e observações resultando em uma lista final com nove grupos. O número pequeno de grupos incluso nesse banco de dados se deve principalmente ao fato de os grupos se repetirem entre as feiras realizadas e as pessoas que trabalham de forma individual de acordo com os dados analisados nas fichas de inscrições ou entrevistas terem algum tipo de relação com os grupos então selecionados.

A seleção para o Projeto Cantina Solidária IV utilizou como base o banco de dados, sendo que da lista apresentada com nove grupos foram escolhidos seis como possíveis potenciais a serem visitados: Associação Comunitária Rural da Mantiba ; Grupos Mulheres Unidas como Formiga; Associação Comunitária do Povoado de Tanquinho de Humildes e Adjacências - Grupo Beiju da Tia Bete; Associação Comunitária De Moita da Onça - grupo "Unidos Venceremos"; Associação Comunitária Povoado Do Caroá; Associação Comunitária de Vila Feliz .Sendo as visitas realizadas com quatro grupos: Associação Comunitária de Vila Feliz e Associação Comunitária Povoado Do Caroá ,Grupo Mulheres Unidas como Formiga, e Associação Comunitária De Moita da Onça - grupo "Unidos Venceremos.

O mapeamento constituiu de análises externas através das entrevistas semiestruturadas realizadas na Comunidade Quilombola da Lagoa Grande. .Buscando dessa forma a integração da relação comunidade $\mathrm{x}$ universidade beneficiando os consumidores através de uma alimentação "mais saudável", tendo conhecimento da origem do produto que está consumindo , além do fortalecimento da comunidade incentivo ao desenvolvimento local e valorização da comunidade, podendo as integrantes da cantinas terem uma diversificação na aquisição de matéria-prima. Foram realizadas 108 entrevistas, sendo 79 mulheres e 29 homens compreendendo a faixa etária de 13 a 76 anos. Onde o destino da produção é principalmente o consumo familiar e comercialização do excedente que é realizado em feiras livres :Centro de abastecimento e Cidade Nova e na comunidade entre os próprios moradores ou para atravessadores, que circulam na região. Dos 82 agricultores que se apresentam interesse em comercializar para as cantinas 11 já forneceram ou fornece alguma matéria -prima para o grupo Sabores do Quilombo. Durante a execução do mapeamento os produtos mais identificados foram frutíferas, sendo que cada agricultor mesmo que não produza "nada" (milho, feijão,mandioca), apresenta um pé de frutífera em seu quintal, que muitas ocorre o desperdício , pois a família não consegue dá conta da produção ou são subutilizados para a produção de um outro produto, como o caso de uma agricultora que utiliza a palha da banana para a produção do bolo de palha, não tem interesse pela banana. 


\section{CONSIDERAÇÕES FINAIS}

O trabalho em seu desenvolvimento permitiu a estruturação do banco de dados IEPS , que surge como uma ferramenta auxiliar no desenvolvimento de atividades da Incubadora auxiliando no desenvolvimento de atividades internas e dos grupos em processo de incubação. Desta forma, a construção do banco de dados possibilitou o levantamento de possíveis agricultores como potenciais fornecedores de matéria-prima, construindo elementos bases para a construção de redes de comercialização e execução de planos de trabalhos subsequentes de bolsistas da IEPS.

A construção de rede nos espaços das Cantinas Solidárias é um processo lento e que busca a integração entre campo e cidade, com fortalecimento da relação entre economia solidária e agricultura familiar, cujas ações não estão isoladas podendo ser observado através do trabalho associado, de uma forma que o agricultor se sinta como parte integrante da comercialização, e não apenas mais um fornecedor de produtos/matéria-prima.

Desta forma, a diversificação de fornecedores pode garantir aos integrantes das Cantinas Solidárias um fortalecimento da agricultura familiar e um estímulo para que o homem do campo não venha desistir das suas atividades, bem como oferece opções de escolha, garantindo que todos/todas envolvidos no processo de comercialização sejam beneficiados. Para isso, o processo de rodízio entre os fornecedores seria uma boa opção para que se garanta a participação diversificada desses agricultores, de forma que uma vez montada a rede, tomariase o cuidado para que não houvesse a formação de monopólios entre os agricultores fornecedores, assim outros agricultores também teriam a oportunidade de oferecer seus produtos/matéria-prima e todos participariam da rede de comercialização.

\section{REFERÊNCIAS}

BRANDÃO, Carlos Rodrigues. Pesquisa participante. São Paulo: Brasiliense, 1999.

BRANDÃO, Carlos Rodrigues. A pesquisa participante: um momento na educação popular. Educação Popular, Uberlândia, v.6,p51-62.jan./dez. 2007.

CARMO, Maristela S.do. A produção familiar como lócus ideal da agricultura sustentável,p.215-238.In: FERREIRA, Angela D.D. \& BRANDENBURG,Alfio (orgs) Para pensar outra agricultura. Curitiba: Ed. UFPR,1998,257p.

\section{IEPS/UEFS Projeto Incubadora de Iniciativas da Economia Popular e Solidária da Universidade Estadual de Feira de Santana, Feira de Santana, Bahia, 2008. IEPS/UEFS Projeto Cantina Solidária I. Feira de Santana, Bahia, 2012.}

IEPS/UEFS. Projeto Cantina Solidária III. Feira de Santana, Bahia, 2016.

LIMA, J. R. O.. Economia popular e solidária e desenvolvimento local solidário: análise dos processos educativos e de economia política inerente à incubação de iniciativas econômicas populares solidárias. Comunicação apresentada no I Seminário do Fórum de Pesquisa da Linha 3 - Educação, Gestão e Desenvolvimento Local Sustentável do PPGEduC/UNEB - SalvadorBA,mai.2012.

MOTTA, Eugênia. Economia Solidária e Agricultura Familiar uma integração necessária. Democracia Viva, Rio de Janeiro, n. 35, p 80-84, jun. 2007. 
PITA, F.; LIMA, J. R. O; LIMA, C. E. S. Normatizando solidariedade: experiência de construção coletiva de regras de uma cooperativa informal de Economia Solidária. Outra Economia, v.9, 2015, p.69.

SOUZA, M. M. O., A utilização de metodologias de diagnóstico e planejamento participativo em assentamentos rurais: o diagnóstico rural/rápido participativo (DRP). EM EXTENSÃO, Uberlândia, v. 8, n. 1, p. 34 - 47, jan./jul. 2009.

THIOLLENT, Michel. Metodologia da pesquisa-ação. São Paulo: Cortez,1986. 